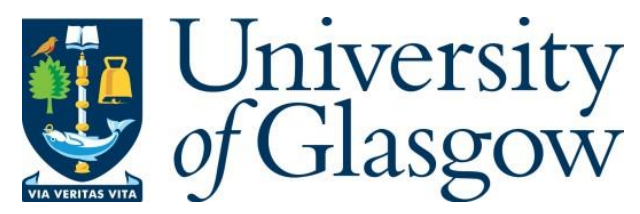

Kelp, C. and Pedersen, N. J.L.L. (2011) Second-order knowledge. In: Bernecker, S. and Pritchard, D. (eds.) The Routledge Companion to Epistemology. Series: Routledge philosophy companions. Routledge: London, pp. 586-596. ISBN 9780415962193.

There may be differences between this version and the published version. You are advised to consult the publisher's version if you wish to cite from it.

http://eprints.gla.ac.uk/140937/

Deposited on: 15 May 2017

Enlighten - Research publications by members of the University of Glasgow http://eprints.gla.ac.uk 
For S. Bernecker and D. Pritchard (eds.): Routledge Companion to Epistemology.

\section{SECOND-ORDER KNOWLEDGE}

Christoph Kelp

University of Leuven

Nikolaj Jang Lee Linding Pedersen

University of California, Los Angeles

University of Copenhagen

\section{Introduction}

Knowledge involves belief. Belief is a propositional attitude, i.e. an attitude that a subject holds towards a proposition. If a subject $S$ knows that $P$ and the proposition $P$ involves no further knowledge attribution, let us say that $S$ possesses first-order knowledge. On the other hand, if $S$ knows that $P$ and the proposition $P$ involves a knowledge attribution, let us say that $S$ possesses higher-order knowledge. The aim of this article is to shed light on the nature of second-order knowledge, a specific kind of higher-order knowledge.

Consider the following cases of knowledge:

(1) Duncan knows that $4+5=9$.

(2) Duncan knows that he knows that $4+5=9$.

(3) Duncan knows that he knows that he knows that $4+5=9$.

In (1) the proposition within the scope of "knows" does not involve a further knowledge attribution, and for this reason (1) presents an example of first-order knowledge. In this respect (1) differs from (2) and (3), which are both examples of higher-order knowledge. More specifically, they are cases of, respectively, second-order and third-order knowledge.

(2) features a knowledge attribution within the scope of another knowledge attribution, while

(3) features a knowledge attribution within the scope of a knowledge attribution that itself lies within the scope of yet another knowledge attribution.

Our discussion of higher-order knowledge will be based on the specific case of second-order knowledge. This will offer significant expository advantages. More importantly, despite the restriction in focus, it will become clear that there is plenty to say. A whole range of interesting issues and questions pertaining to second-order knowledge will emerge as we proceed. It is worth noting, however, that the kinds of considerations about second-order knowledge that we will be offering here are also relevant to cases of knowledge of higher orders-if properly extended or modified.

We will approach the task of shedding light on second-order knowledge by discussing it in relation to the following distinction and principle-each of which has featured prominently in the epistemological literature:

(i) Internalism/externalism: according to internalists about warrant, if a subject $S$ is warranted in believing that $P$, then the reasons that underwrite $S$ 's warrant have to be accessible to $S$ by reflection-that is, by introspection, a priori reasoning, or memory-alone. Externalists about warrant deny this idea. They claim that 
For S. Bernecker and D. Pritchard (eds.): Routledge Companion to Epistemology.

warrant-giving reasons can sometimes be tied to features of $S$ 's means of beliefacquisition, possibly in combination with features of the environment they operate in, and that these features need not be accessible via reflection alone. (Contributions to the discussion of internalism/externalism, as characterized here, or alternative ways of drawing the distinction (and views that result from these) include Alston 1986, Bonjour 1980 and 1992, Brown 2007, Conee and Feldman 2001, Goldman 1979 and 1999, and Pryor 2001. Kornblith 2001 is a collection of papers on internalism/externalism in epistemology, while Goldberg 2007 is a collection of recent papers on the internalism/externalism divide in semantics and epistemology. Note that for present purposes we will not understand "warrant" in the way that Plantinga 1993 does, i.e. as that which renders knowledge when added to true belief.)

(ii) KK-principle: in its standard formulation the KK-principle says that, if $S$ knows that $P$, then $S$ knows that $S$ knows that $P$. We can write this formally as follows: $K_{S} P \rightarrow K_{S} K_{S} P$ (where " $K_{S}$ " is read " $S$ knows that ..." and "..." is to be replaced by a proposition).

\section{Second-order knowledge and the internalism/externalism distinction}

Before we turn to the task of showing how the internalism/externalism distinction can be used to gain insights into the nature of second-order knowledge, a clarificatory remark is in order. The distinction between internalism and externalism has been introduced as pertaining to warrant. How, then, can it be relevant to the nature of second-order knowledge?

There is a fairly straightforward answer to this question. The answer is this: most epistemologists take warrant to be a necessary condition on knowledge. One cannot know that $P$ without also being warranted in believing that $P$. For this reason, internalists about warrant are also internalists about knowledge in an interesting sense: knowledge is subject to a substantial internalist constraint. The same kind of point applies if we consider knowledge and externalism about warrant, although, of course, in this case it is the other way around. Externalists about warrant maintain that there is no substantial internalist constraint on knowledge. (Strictly speaking, they only do so if it is also assumed that the warrant component of knowledge is the only one underwritten by reasons.) Typically they hold this view, because they hold the further view that being warranted is a property that beliefs possess (or fail to possess) in virtue of being produced by a certain kind of method or process in a certain kind of environment. Warrants are thus underwritten by features of the relevant means of belief-acquisition, possibly in conjunction with features of the environment.

As mentioned above, the debate over internalism and externalism is quite extensive. For our present purposes, though, we need not dive into the intricate details of the debate. It will suffice to make an observation about what has fueled it -if not fully, then at least to a considerable extent. Part of what has motivated the debate is an internalist monist outlook on warrant. Warrant monism has it that the nature of warrant is one and the same, always and anywhere. The internalist monist maintains that all warrants are of an internal character in the sense mentioned earlier, i.e. in the sense that the reasons underwriting all warrants must be accessible to the warranted individual through reflection alone. What we will now do is to 
For S. Bernecker and D. Pritchard (eds.): Routledge Companion to Epistemology.

consider second-order knowledge against the background of internalist warrant monism and then against the background of warrant pluralism-the view that there is at least one viable internalist species of warrant and at least one viable externalist species of warrant too.

Suppose that internalist warrant monism is correct and consider a case of secondorder knowledge-rendered formally: $K_{S} K_{S} P$. What can be said about the nature of this instance of knowledge? The assumption of internalist monism enables us to make some progress with respect to this question: both knowledge attributions have to be understood along internalist lines. Formally, we can write this by adding a superscript to our stock of symbols: $K_{s}^{I} K_{s}^{I} P$.

To get a specific point of focus let us return to the example of second-order knowledge given above. Duncan knows that he knows that $4+5=9$. Starting with the firstorder knowledge attribution, internalism tells us that whatever warrant-giving reasons are involved in Duncan's knowledge that $4+5=9$ must be accessible via introspection, a priori reasoning, or memory. One way this constraint could be satisfied is by Duncan's knowing that $4+5=9$ on the basis of a proof in elementary arithmetic. In that case Duncan's warrant-giving reasons - all provided by the proof — are ones that he can access a priori. He can access them by thinking alone. Moving on to the second-order knowledge attribution, internalist monism dictates that this too be subjected to an accessibility constraint. How could this be satisfied? Here is one way: Duncan might believe that he knows that $4+5=9$, because he has examined the pedigree of his own proof, reached the conclusion that it is a solid proof that establishes a true conclusion, and that he knows that $4+5=9$ for this reason. Duncan can be warranted in believing that he knows that $4+5=9$ via introspection. He can "look inside," as it were, and track his belief. This, in turn, is his warrant-giving reason and something that is accessible to him through reflection alone.

Let us now turn to externalism and see how it might connect with the monism/pluralism issue and the nature of second-order knowledge. As understood above, externalism is the negation of internalism - that is, the negation of the claim that the reasons that underwrite all warrants must be accessible to the warranted individual by reflection alone. Externalism thus understood is compatible with both what we might call "extreme externalist warrant monism" and what was labeled "warrant pluralism" earlier. The former is a more radically externalist view than the latter. The extreme externalist warrant monist maintains that the nature of warrant is always and anywhere the same in that no instance of warrant involves a satisfaction of the accessibility constraint endorsed by the internalist. This radical form of externalism strikes us highly implausible, and we will not dwell on the view any further. Instead we turn to warrant pluralism. Not only is the view more plausible than extreme externalist monism - as we shall see, it can also be used to shed some light on the nature of second-order knowledge.

According to the warrant pluralist, some cases of warranted belief involves a satisfaction of the internalist accessibility constraint, while others do not. (Authors who are sympathetic to some version of warrant pluralism include Tyler Burge (1993, 2003), Alvin Goldman (1988), and Crispin Wright (2004, 2008).) Warrant pluralism thus leaves conceptual room for two kinds of uniform and two kinds of non-uniform second-order knowledge. The first kind of uniform second-order knowledge subsumes any case of second-order knowledge where both warrants are internalist, while the second kind subsumes any case in which both warrants are externalist (in the sense of not satisfying the internalist constraint). The first kind of non-uniform second-order knowledge is any case where the "inner" knowledge attribution is internalist and the "outer" one externalist, while, for the second kind, it is the other way around. 
For S. Bernecker and D. Pritchard (eds.): Routledge Companion to Epistemology.

Using the formalism that we have relied on so far what warrant pluralism does is to accommodate the following four different species of second-order knowledge, or at least their possibility:

Second-order knowledge:

- Uniform

○ $K_{S}^{I} K_{S}^{I} P$

○ $K_{S}^{E} K_{S}^{E} P$

- Non-uniform

○ $K_{S}^{I} K_{S}^{E} P$

○ $K_{S}^{E} K_{S}^{I} P$

The considerations just offered suggest that whether one is an internalist warrant monist or a warrant pluralist is relevant to answering the question what there is to say about the nature of second-order knowledge. On the internalist monist view, second-order knowledge is tied thoroughly to reflection. Both knowledge attributions involved in cases of second-order knowledge are subject to the constraint that warrant-giving reasons have to be accessible through reflection alone. The warrant pluralist begs to differ: second-order knowledge need not have such a thoroughly reflective character. Some cases of second-order knowledge may involve two warrants that both satisfy the internalist accessibility constraint $\left(K_{S}^{I} K_{S}^{I} P\right)$. However, as just seen, the pluralist landscape of warrants is sufficiently varied that this will not hold across the board. This is one of the things that the uniform externalist cases of second-order knowledge $\left(K_{S}^{E} K_{S}^{E} P\right)$ and the non-uniform cases $\left(K_{S}^{I} K_{S}^{E} P\right.$, or $\left.K_{S}^{E} K_{S}^{I} P\right)$ serve to illustrate.

\section{The KK-principle}

We will now turn to perhaps the most widely discussed issue in the debate over secondorder knowledge, the KK-principle. To begin with, recall the standard formulation of the principle:

Standard-KK $\quad K_{S} P \rightarrow K_{S} K_{S} P$

This principle is not obviously true and so it requires defense. A full defense of the KKprinciple will show not only why we ought to buy into it, but also that it is validated by one's preferred account of (first-order) knowledge. And already at this stage, there is some reason to believe that Standard-KK does not hold. After all, knowledge requires belief. If it turns out to be so much as possible to know a proposition yet fail to believe that one does, Standard-KK will be refuted. Since it is at least possible that one fails to register that one knows some proposition-due to a lapse of attention, say-and thus, that one fails to form the corresponding belief, one might think that the prospects for Standard-KK are rather $\operatorname{dim}$.

In view of such difficulties, some have tried to restrict the KK-principle. Perhaps the most common move here is to weaken it: if one knows that $P$ then one is in a position to know 
For S. Bernecker and D. Pritchard (eds.): Routledge Companion to Epistemology.

that one knows that $P$. Or again, formally (where " $\nabla K_{S}$ " is read as " $\mathrm{S}$ is in a position to know ..." and "..." is to be replaced by a proposition)

$$
\text { Weak-KK } \quad K_{s} P \rightarrow \diamond K_{S} K_{s} P
$$

There are various ways of spelling out the notion of being in a position to know. Crucially, however, all of these ways maintain that being in a position to know that $P$ does not require belief that $P$. This will, of course, remedy the above defect. It remains to be shown whether there is good reason to accept Weak-KK and whether it is validated by the correct first-order account of knowledge.

The answer to the question concerning the KK-principle is often viewed as reflecting the divide between internalism and externalism about warrant. Internalists, or to be more precise, internalist monists, tend to be more sympathetic to the KK-principle, whilst externalists tend to reject it (some, e.g. Williams 1991, have gone as far as cashing out the distinction between internalism and externalism in terms of their diverging stances on the KK-principle). It is not hard to see why this should be so. To begin with, externalists tend to reject the KK-principle even in its weak form because they tend to construe at least some of the processes that are crucial to the delivery of the first-order beliefs-such as perception, testimony etc.-not only as being different than but also as being independent from the ones that are crucial to the delivery of the second-order beliefs-such as introspection. If these processes are both separate and independent, however, it is possible that one-the first-order process, say-operates in such a way as to deliver the warrant, while none of the second-order ones follow suit. In such a situation the subject may acquire a first-order warrant whilst not even being in a position to acquire a second-order warrant-hence the externalist's rejection of even Weak-KK.

Contrast this position with the one favored by the internalist. If as internalists think, the subject's reasons that underwrite her warrant for $P$ must be accessible to her by reflection alone, then through reflecting she can come to know that she has a warrant for $P$. Or, in other words, she has an internalist warrant that she has a warrant for $P$. If, as some internalists are also happy to grant, belief is luminous in the sense that one can know by reflection alone that one believes $P$ on grounds $G$ whenever one does, she also has an internalist warrant that she believes that $P$ and that this belief is suitably grounded in her warrant for $P$. Since in order to know $P$ she must have an internalist warrant for $P$, she thus has an internalist warrant (a) that she has an internalist warrant for $P$, (b) that $P$ is true, (c) that she believes $P$ and (d) that her belief that $P$ is grounded in her warrant for $P$. Given an internalist monist conception of knowledge according to which one knows that $P$ just in case one truly believes $P$ on the basis of an internalist warrant for $P$, it follows that our subject has an internalist warrant that she satisfies all the conditions for knowledge that $P$. In other words, she has an internalist warrant that she knows that $P$. Finally, suppose that to be in a position to know that $P$ is to be but a suitably based belief that $P$ away from knowledge that $P$. By the present internalist account of knowledge that means that a subject is in a position to know $P$ if and only if she has an internalist warrant for $P$ and $P$ is true. Recall that we have just shown that, by the lights of the present account, if a subject knows $P$ she has an internalist warrant that she does. Since if she knows $P$, it must also be true that she knows $P$, the internalist account of knowledge under consideration yields that, if she knows $P$ she has an internalist warrant that she knows $P$ and she does know $P$. By the above account of being in a position to know, it follows that if she knows $P$ she is in a position to know that she 
For S. Bernecker and D. Pritchard (eds.): Routledge Companion to Epistemology.

knows $P$. Thus we have one way in which an internalist monist conception of knowledge validates Weak-KK.

\section{Problems and objections to the KK-principle}

\section{Gettier cases}

Let us now move on to some objections to the KK-Principle. Some, including card-carrying internalists (cf. Chisholm 1986: 90), have thought that the Gettier problem not only constitutes the demise of the kind of internalist conception of knowledge sketched above, but also highlights that the prospects even for a weak version of the KK-principle are dim.

One way of articulating their worry is as follows: Gettier cases show that knowledge cannot just be internalistically warranted true belief. They show that a further external condition for knowledge is required. Given that the condition is external, however, it will be impossible to come to know by reflection alone that one satisfies it. But, the thought continues, in order to be in a position to know that one knows one must, by internalist lights, at least have an internalist warrant that one satisfies all the conditions for first-order knowledge. So, even the internalist will be unable to validate Weak-KK. If even the internalist cannot do this, the prospects for Weak-KK may appear to be rather dim.

There are a number of ways in which this worry can be allayed. The one we would like to focus on here concerns the possibility of warrant pluralism, discussed briefly above. Suppose internalists agree that knowledge requires a degettierisation condition in addition to internalistically warranted true belief. If they are willing to countenance warrant pluralism, they may be able to rescue Weak-KK by putting to use the idea of an externalist warrant that one has by default — call it "entitlement." Suppose internalists can argue that subjects are entitled to believe that their first-order beliefs are not gettierised, which seems plausible if a case can be made that there is any proposition we are entitled to believe. Suppose, furthermore, they are willing to grant mixed warrants constituted, on the one hand, by the internalist warrant that one satisfies the internalist warrant, truth, belief and grounding condition for knowledge and, on the other hand, by the entitlement that one has that one satisfies the degettierisation condition. Then they may be able to validate a version of the KK-principle after all. For now, at least in the default case, the subject does have a mixed warrant that she possesses first-order knowledge. Again, if to be in a position to know is to be but a suitably based (and, we must now add, degettierised) belief away from knowledge, and if knowledge is degettierised, internalistically warranted and true belief, then, if the subject does have first-order knowledge, she is in a position to know that this is so.

What is also interesting about this line is that it is available also to the externalist. Just like the internalist, the externalist may wish to countenance the possibility of an entitlement to the proposition that we satisfy the conditions for first-order knowledge and venture to defend an externalist version of the KK-principle. Notice furthermore that, as opposed to the internalist, the externalist will not even have to grant the possibility of mixed warrants. After all, entitlement is generally conceived of as an externalist type of warrant. So, somewhat surprisingly, even if the prospects of a purely internalist version of the KKprinciple are dim, externalists who are willing to grant that we have default entitlements that the conditions for first-order knowledge are satisfied may be able to countenance a purely externalist version of the KK-principle. (McHugh Forthcoming exploits the notion of 
For S. Bernecker and D. Pritchard (eds.): Routledge Companion to Epistemology.

entitlement to defend a version of the KK-principle that he claims to be compatible with both internalist and externalist conceptions of knowledge.)

\section{Children and Animal Knowledge}

Another standard objection to the KK-principle starts from the following observation: it is plausible that small children and certain animals can have basic first-order knowledge of the world, e.g. that there is something red or that there is food, whilst not possessing the reflective abilities and concepts requisite to acquire the corresponding second-order knowledge. They might lack the very concept of knowledge needed to grasp the proposition that they know. If this is correct, it becomes very plausible that even Weak-KK fails. Small children and animals know things but since they lack the very concept of knowledge, they are not even in a position to know that they know (Alston 1989: 173; Dretske 2004: 176).

It is noteworthy that there is scientific evidence backing the crucial premises of this argument. Studies in developmental psychology suggest that children as young as 2-3 months are able to discriminate between just as many colors as adults and children at the age of 4 months are able to perceive colors categorically. It is tempting to attribute basic perceptual knowledge of colors at least to four-month-olds. Moreover, scientists seem to agree that even small children possess "sophisticated knowledge about objects." (Cohen and Cashon 2003: 76). Just how early children are able to attain such knowledge is disputed. While some researchers attribute this kind of knowledge to children as young as 2.5 months of age, others think that they do not possess it until they have reached 10-12 months (Cohen and Cashon 2003: 76-77). Thus, even on a conservative interpretation of these results, there is good reason to believe that children can typically have first-order knowledge before the age of 1 . At the same time, other studies suggest that children tend not to be able to master the distinction between guessers and knowers until the age of 4 (Povinelli and DeBlois 1992). In view of this, one might reasonably wonder whether they can be credited with a concept of knowledge. After all, even if they were to use the word "know" and its cognates in speech, it might well be that the concept expressed by this is some more primitive, more inclusive concept than the concept we, adult humans, express by this word. So, there is reason to believe that the above argument against the KK-principle finds support in results from recent studies in developmental psychology.

Again, there are moves to be made here for the champion of the KK-principle. Perhaps the most obvious one is to place an additional restriction on the principle to the effect that the agent can grasp the proposition that she knows (McHugh Forthcoming; Ginet 1970 discusses and defends a version of the KK-principle along the same lines). One disadvantage of this move is that it seems to demote the KK-principle's status: instead of capturing a fundamental truth about knowledge it now captures a truth about certain kinds of cognitive agent, i.e. those capable of grasping propositions about first-order knowledge. Alternatively, one could insist that even small children and animals are in a position to know that they have knowledge where this means that they are but a suitably based (and degettierised) belief away from second-order knowledge. Of course, small children and animals are in no position to form a belief that they know. It remains true, however, that they are but a suitably based (and degettierised) belief away from knowing that they know. Now, it might be objected that in order to have a warrant for some proposition $P$ one already must have the concepts needed to grasp $P$ (Feldman 2005: 111). While this may be plausible for warrants that the subject needs to achieve, it is far from clear that this also 
For S. Bernecker and D. Pritchard (eds.): Routledge Companion to Epistemology.

needs to be the case for types of warrant that can be held by default. Since entitlement is just such a type of warrant, the champion of the KK-principle can avoid this objection by construing the relevant second-order warrants as entitlements. So, it seems that some version of the KK-principle may remain defensible even in the face of the objection from children and animal knowledge.

\section{Williamson's Anti-luminosity Argument}

The last objection against the KK-principle we will discuss here is due to Timothy Williamson. Williamson argues against the possibility of "luminous conditions." Roughly, a condition is luminous if and only if it is such that if and when it one is in it, one is also in a position to know that it one is in it. Alternatively, a condition $C$ is luminous just in case

Luminosity For all subjects $S$ and times $t$, if at $t S$ is in $C$ then at $t \mathrm{~S}$ is in a position to know that $S$ is in $C$.

The KK-principle can then be interpreted as stating that the condition of knowing a proposition is luminous.

Williamson ventures to show that conditions such that one can gradually move from times at which one is in them to times at which one isn't cannot be luminous. The crucial step in Williamson's argument is to show that in conjunction with a plausible instance of the so-called "safety" condition on knowledge, according to which in order know a proposition, $P$, one must avoid false belief in $P$ across relevantly similar situations, Luminosity yields the paradoxical result that it is impossible to move gradually from times at which one is in the allegedly luminous condition to times at which one isn't.

In order to see how the argument works, let $C$ be any a condition that admits of gradual movement in the relevant sense, $S$ any cognitive agent with limited cognitive capacities and $t_{i}$ and $t_{i+1}$ any two adjacent instants in a series of instants that describes $S$ 's gradual movement from times at which $S$ is in $C$ to times at which $S$ is not in $C$. Furthermore, let the instants in the series be separated by intervals so small that, due to $S$ 's limited cognitive capacities, $S$ cannot distinguish between them with respect to whether $S$ is in $C$. Since, at the same time, plausibly, any two adjacent instants in the series are relevantly similar to one another, the only way in which, at any one instant, $S$ can avoid false belief that $S$ is in $C$ across relevantly similar situations is if, at the adjacent instant, $S$ continues to be in $C$. Otherwise put, the following is a plausible instance of the safety condition:

Safety For any two adjacent instants, $t_{i}$ and $t_{i+1}$, if at $t_{i} S$ knows that $S$ is in $C$ then at $t_{i+1} S$ is in $C$.

Now Williamson assumes a conception of what it takes to be in a position to know that is closely related to but slightly stronger than the one outlined above: "If one is in a position to know $P$, and one has done what one is in a position to do to decide whether $P$ is true, then one does know P." (Williamson 2000: 95) Supposing, as Williamson may in his example, that $S$ does what she can to determine whether $P$ is true, we get that if, at $t_{i}$, $S$ is in $C$, then, at $t_{i}, S$ knows that $S$ is in $C$. By Safety we can derive: at $t_{i+1}, S$ is in $C$. Since Luminosity holds for all times and Safety for any two adjacent instants $t_{i}$ and $t_{i+1}$ in the series, continuous application of the two principles will show that if, at any time, $S$ is in $C$, at all times $S$ is in $C$ - contrary 
For S. Bernecker and D. Pritchard (eds.): Routledge Companion to Epistemology.

to the assumption that $S$ can move gradually from times at which $S$ is in $C$ to times at which $S$ isn't in $C$. So, conditions that admit of such gradual movement cannot be luminous.

In order to put the anti-luminosity argument to work against the KK-principle, it remains to be shown that one can move gradually from the condition of knowing a proposition to not knowing it. Fortunately, this is fairly easily done. To see this, consider the following example: $S$ is looking at a surface the color of which gradually changes from red to orange along the color circle over a time span of 24 hours. Suppose, at the outset, $S$ believes on the basis of visual-perceptual evidence that the surface is red. Since the surface is clearly red, surely she also knows that it is red. However, as time passes, the visual perceptual evidence grounding her belief changes gradually from red to orange. The evidence grounding her belief that the surface is red thus becomes gradually weaker and weaker until it is no longer strong enough to give her knowledge that it is red. So, it is possible to gradually move from the condition of knowing a proposition-here, that the surface is red-to the condition of not knowing it. The anti-luminosity argument applies. The KK-principle fails.

Powerful as Williamson's argument may be, it does not go uncontested. Some have objected to the safety principle on which the argument rests (e.g., Neta and Rohrbaugh 2004; Comesaña 2005; Kelp 2009). It is not clear, however, whether this will block the antiluminosity argument in general or its specific application to the KK-principle. For, even if it can be shown that there are counterexamples to safety, it does not follow that safety fails in the kind of example at issue in Williamson's argument. Indeed one may think that the specific instances of safety Williamson needs are independently plausible. Others have tried to rescue a version of the KK-principle for certain types of knowledge (Dokic and Égré 2009). It is worth noting that there are positive arguments for the luminosity of certain conditions, vir. ones that are constituted by the subjects' believing them (cf. Weatherson 2004; Conee 2005). However, note also that, since a subject's knowledge is certainly not constituted by her belief that she knows, this strategy must not be expected to rescue the KK-principle from Williamson's argument.

For present purposes we would like to develop a response on behalf of champions of the KK-principle that can be traced back to Hintikka (1970). Hintikka responds to objections to his version of the KK-principle by restricting the principle to what he calls "a strong sense of the concept of knowledge," the sense of the concept Hintikka claims to be at issue in most epistemological literature. On the face of it, Hintikka seems to be suggesting that the concept of knowledge is ambiguous. So understood his proposal may not seem very attractive. However, there is a related way of interpreting Hintikka's remarks that is very much in line with contextualism, a prominent view in recent epistemology. According to the contextualist, the term "knows" and its cognates are context-sensitive. They express different relations in different contexts (the most prominent champions of this kind of contextualism in epistemology are Stewart Cohen (e.g. 1988), Keith DeRose (e.g. 1995), and David Lewis (e.g. 1996)). Crucially, context determines just how strong a warrant one needs to have in order to count as "knowing." We can once again express this suggestion formally by introducing a superscript indicating the strength of warrant needed for "knowledge": $K_{S}^{0} P, K_{S}^{1} P, K_{S}^{2} P$, etc. The rule here is: the higher the numeral in the superscript, the stronger the warrant needed for "knowledge," i.e. the stronger the knowledge relation.

We can now interpret Hintikka's response as claiming that the KK-principle holds in contexts in which "knows" expresses a suitably strong knowledge relation. That is to say, we get: $K_{s}{ }^{n} P \rightarrow \diamond K_{s}{ }^{n} K_{s}{ }^{n} P$ for suitably large $n$. If Williamson's argument is sound, it is hard to see how any being with limited cognitive capacities could ever stand in such a strong knowledge 
For S. Bernecker and D. Pritchard (eds.): Routledge Companion to Epistemology.

relation (except perhaps to a very limited range of propositions). However, contextualists are typically happy to grant that at least in some (typically philosophical) contexts "knows" may express such a strong relation. If so, contextualists may be able to countenance a version of the KK-principle even if Williamson's anti-luminosity argument goes through. What is more, it may even be possible that contextualists allow for a kind of mixed KK-principle according to which if one stands in a very strong knowledge relation to $P$ one may be in a position to attain some weaker knowledge relation that one stands in some (potentially different but also) weaker knowledge relation to $P$. Formally, $K_{S}^{n} P \rightarrow \diamond K_{S}^{n-m} K_{S}^{n-o} P$ may be defensible for suitably chosen $n, m$ and $o$ by contextualist lights. Whether it is will, of course, depend on the details of one's contextualist theory. To take just one example, consider a contextualist theory that countenances knowledge relations governed by different epistemic conditions. (Such a view has recently been proposed in Brogaard (2004).) More specifically, suppose that a subject $S$ stands in the weakest knowledge relation countenanced, $K_{S}^{0} P$, just in case $S$ safely believes the target proposition, $P$, i.e. $S$ avoids false belief in $P$ across relevantly similar situations or, in terms of a possible worlds semantics for the relevant modality, across close possible worlds. At the same time, the contextualist theory also countenances knowledge relations that require not only safely believing the target proposition but also avoiding false belief in it in the region of modal space stretching out to and including the closest worlds at which any error possibility under consideration in context is true. Since the closest such worlds need not be close, our contextualist will have to countenance knowledge relations that are stronger than $K_{S}^{0} P$. Since the distance from actuality of the closest such worlds may vary depending on the nature of actuality and the content of the relevant error possibilities, our contextualist may want to countenance a variety of knowledge relations- $K_{s}^{1} P, K_{s}{ }^{2} P$ and so on-the strength of which depends on how far out in modal space we have to go in order to reach the closest worlds at which they obtain. Now, since " $K_{S}^{0} P$ " is true just in case $S$ safely believes $P$, “ $\diamond K_{S}^{0} K_{S}^{0} P$ " will be true just in case $S$ 's belief in $P$ is safely safe: $S$ must avoid error not only at worlds close to actuality but also at worlds close to these close worlds. Now, let $b$ be the outer boundary of worlds close to worlds close to actuality. Furthermore, let $K_{S}^{i} P$ be any knowledge relation requiring safety and the extra condition such that satisfying the extra condition requires avoiding false belief across a range of worlds stretching beyond $b$. In order to stand in such a knowledge relation to $P, S$ must of course believe $P$. Moreover, $S$ must avoid false belief in $P$ within the boundaries of $b$, that is, at worlds close to worlds close to actuality. So, in order to stand in such a knowledge relation to $P, S$ must believe $P$ and $S$ 's belief must be safely safe. If so, $S$ also satisfies " $\diamond K_{S}^{0} K_{S}^{0} P$ ". We thus have a contextualist theory that validates $K_{S}^{i} P \rightarrow \diamond K_{S}^{0} K_{S}^{0} P$. (And, as opposed to the Hintikka-style KK-principle, it is far from clear that no one with limited cognitive capacities will ever satisfy " $K_{S}^{i} P$ ". On the contrary, if such subjects can satisfy " $K_{S}^{0} K_{S}^{0} K_{S}^{0} P$ ” then they may also be expected to satisfy " $K_{S}^{i} P$ ”' for suitably chosen $i$.)

\section{The social aspect of second-order knowledge}

Above our discussion of second-order knowledge has focused entirely on what might aptly be called "self-attributive" cases. That is, cases where $S$ knows that $R$ knows that $P$, and $S$ and $R$ are identical (reflected, at the formal level, by the subscripts' being the same, i.e. $\left.K_{s} K_{S} P\right)$. We will now drop the assumption of identity and assume its negation instead. This 
For S. Bernecker and D. Pritchard (eds.): Routledge Companion to Epistemology.

will serve as a natural starting point for a brief discussion of the social aspect of secondorder knowledge.

Let's use the label "multi-attributive" for any case of second-order knowledge where $S$ and $R$ are not identical. If we suppose that Bob and Jack are brothers, the following is an example of multi-attributive second-order knowledge:

Bob knows that Jack knows that no solution exists for the equation $a^{n}+b^{n}=$ $c^{n}$ for positive integers $a, b, c$, and $n$ and $n>2$.

Cases like (4) are interesting for several reasons. One quite simple reason is that it serves to highlight the social nature that second-order knowledge sometimes has. (4) reflects the fact that we-or most of us, anyway-do not live in complete epistemic isolation. We are part of epistemic communities, groups that involve other agents with whom we interact and to whom we bear significant epistemic connections.

Another reason why multi-attributive second-order knowledge is interesting is that it points to a certain principle of knowledge transmission:

$$
K_{S} K_{R} P \rightarrow K_{S} P
$$

(KTP) will strike many as plausible, at least to the extent that it is thought that we often gain knowledge by knowing that someone else knows something. Applying this idea to the BobJack example, one might think that, by knowing that Jack knows Fermat's Last Theorem, Bob knows the theorem too. How could this be? Well, perhaps Bob-who has no specialist knowledge about mathematics - has noticed Jack working on a reconstruction of Wiles' proof of the theorem and eventually heard him utter, "I've nailed it! I've finally managed to reconstruct Wiles' proof and thereby shown that no solution exists for the equation $a^{n}+b^{n}$ $=c^{n}$ where $a, b, c, n$ are all positive integers and $n>2$." Let us suppose that Jack-a bit of mathematical prodigy - is not just warranted in believing Fermat's Last Theorem in the situation at hand, but that he knows it. Furthermore, suppose that on the basis of his observation of Jack and Jack's utterance, Bob knows that Jack knows Fermat's Last Theorem. But does Bob also know the theorem? This is just another way of asking whether (KTP) holds in this particular case.

(KTP) has some prominent advocates-Hintikka, just to mention one (cf. Hintikka 1962). However, even if we suppose that advocates of (KTP) are right in maintaining that the principle holds, a number of observations should be made so as to avoid confusion about what the principle says and, just as importantly, what it does not say. In particular, it must be borne in mind that, although any instance of (KTP) involves the idea that subject $S$ gains knowledge by knowing that subject $R$ possesses knowledge, the specific warrant involved in R's knowledge is not automatically transmitted to, or inherited by, S. This is so even if $R$ is fully aware of what the source of $R$ 's knowledge-and warrant-is. The Bob and Jack example will serve nicely to drive this point home. Jack's knowledge-and warrant for believing-that Fermat's Last Theorem is true is based on the proof he has constructed. Bob is fully aware of this. However, it should be clear that this does not make Bob's warranted belief in the theorem-and his corresponding knowledge-proof-based. He is not capable of following the proof, for one. If anything, the warrant possessed by Bob is based on Jack's testimony, on his assertion of Fermat's Last Theorem. The nature of testimonial warrant and knowledge is a complex and much debated issue, and one that, unfortunately, we cannot 
For S. Bernecker and D. Pritchard (eds.): Routledge Companion to Epistemology.

pursue any further here (Burge 1993 and Coady 1992 are important contributions to the debate; Lackey and Sosa 2007 is a collection of recent papers).

\section{References}

Alston, W. (1986) "Internalism and Externalism in Epistemology," Philosophical Topics 14: 179-221. Reprinted in Kornblith 2001.

— (1989) Epistemic Justification: Essays in the Theory of Knowledge, Ithaca, NY: Cornell University Press.

BonJour, L. (1980) "Externalist Theories of Empirical Knowledge," Midwest Studies in Philosopby 5: 53-74. Reprinted in Kornblith 2001.

- (1992) "Externalism/Internalism," in J. Dancy and E. Sosa (eds.) Blackwell Companion to Epistemology, Oxford: Blackwell.

Brogaard, B. (2004) “Contextualism, Scepticism, and the Gettier Problem," Synthese 139: 36786.

Brown, J. (2007) "Externalism in Mind and Epistemology," in S. Goldberg (ed.) Internalism and Externalism in Semantics and Epistemology, Oxford: Oxford University Press: 13-34.

Burge, T. (1993) “Content Preservation,” Philosophical Review 102: 457-88.

_ (2003) "Perceptual Entitlement," Philosophy and Phenomenological Research 67: 503-48.

Chisholm, R. (1986) “The Place of Epistemic Justification,” Philosophical Topics 14: 85-92.

Coady, C. A. J. (1992) Testimony: A Philosophical Study, Oxford: Clarendon Press.

Cohen, L.B. and Cashon C.H. (2003) "Infant Perception and Cognition," in R. Lerner et al. (eds.) Handbook of Psychology: Developmental Psychology Vol. 6, Hoboken, NJ: Wiley.

Cohen, S. (1988) "How to be a Fallibilist," in J. Tomberlin (ed.) Philosophical Perspectives 2: 81123.

Comesaña, J. (2005) “Unsafe Knowledge,” Synthese 146: 395-404.

Conee, E. (2005) "The Comforts of Home," Philosophy and Phenomenological Research 70: 44451.

Conee, E. and Feldman, R. (2001) "Internalism Defended," American Philosophical Quarterly 38: 1-18. Reprinted in Kornblith 2001.

DeRose, K. (1995) “Solving the Skeptical Problem," The Philosophical Review 104: 1-52. 
For S. Bernecker and D. Pritchard (eds.): Routledge Companion to Epistemology.

Dokic, J. and Égré, P. (2009) "Margins for Error and the Transparency of Knowledge," Synthese 166: 1-20.

Dretske, F. (2004) “Externalism and Modest Contextualism,” Erkenntnis 61: 173-86.

Feldman, R. (2005) "Respecting the Evidence," in J. Hawthorne (ed.) Philosophical Perspectives 19: 95-119.

Ginet, C. (1970) "What Must be Added to Knowing to Obtain Knowing That One Knows?" Synthese 21: 163-86.

S. Goldberg. (2007) Internalism and Externalism in Semantics and Epistemology, Oxford: Oxford University Press.

A. Goldman. (1979) "What is Justified Belief?" in G. Pappas (ed.) Justification and Knowledge, Dordrecht: D. Reidel: 1-23.

- (1988) "Strong and Weak Justification," in J. Tomberlin (ed.) Philosophical Perspectives 2: 51-69.

_ (1999) "Internalism Exposed," Journal of Philosophy 96: 271-93. Reprinted in Kornblith 2001.

Hintikka, J. (1962) Knowledge and Belief: An Introduction to the Logic of the Two Notions, Ithaca, NY: Cornell University Press.

(1970) “'Knowing that one knows' reviewed," Synthese 21: 141-62.

Kelp, C. (2009) “Knowledge and Safety,” Journal of Philosophical Research 34: 21-31.

H. Kornblith. (2001) Epistemology: Internalism and Externalism, Oxford: Blackwell.

Lackey, J. (2008) Learning from Words: Testimony as a Source of Knowledge, Oxford: Oxford University Press.

Lackey, J. and Sosa, E. (eds.) (2007) The Epistemology of Testimony, Oxford: Oxford University Press.

Lewis, D. (1996) “Elusive Knowledge,” Australasian Journal of Philosophy 74: 549-67.

McHugh, C. (Forthcoming) "Self-knowledge and the KK-principle," Synthese.

Neta, R. and Rohrbaugh, G. (2004) "Luminosity and the Safety of Knowledge," Pacific Philosophical Quarterly 85: 396-406.

Povinelli. D. J. and DeBlois, S. (1992) "Young Children's Understanding of Knowledge Formation in Themselves and Others," Journal of Comparative Psychology 106: 228-38.

Plantinga, A. (1993) Warrant: The Current Debate, Oxford: Oxford University Press.

Weatherson, B. (2004) “Luminous Margins,” Australasian Journal of Philosophy 82: 373-83. 
For S. Bernecker and D. Pritchard (eds.): Routledge Companion to Epistemology.

Williams, M. (1991) Unnatural Doubts: Epistemological Realism and the Basis for Scepticism, Oxford: Blackwell.

Williamson, T. (2000) Knowledge and Its Limits, Oxford: Oxford University Press.

C. Wright. (2004) "Warrant for Nothing (Foundations for Free)?" Proceedings of the Aristotelian Society 78: 167-212.

- (2008) "Internal-External: Doxastic Norms and the Defusing of Skeptical Paradox," Journal of Philosophy 105: 501-17. 